\title{
OBITUARY
}

\section{Professor Giorgio Forti}

\section{R.C. JENNINGS}

Dipartimento di Bioscienze, Università di Milano, Milano, Italy e-mail: robert.jennings@unimi.it

Professor Giorgio Forti passed away on March 1, 2021 in his Milano home. Giorgio was the father of modern photosynthetic research in Italy. His contribution to photosynthesis studies for over 50 years is respected and acknowledged internationally.

The basic scientific interests of Giorgio were in the field of biochemistry and physiology of photosynthetic electron transport. His pioneering research on ATP synthesis generated by the Mehler reaction (Forti and Jagendorf 1961) and the cyclic electron transport around photosystem I (Forti and Parisi 1963) gained him international recognition, as did the biochemical studies on the key enzyme ferredoxin $\mathrm{NADP}^{+}$oxidoreductase (Forti and Sturani 1968), pivotal in both the above-mentioned processes. This enzyme was shown to be localized mostly in the partition zones between the thylakoids which excluded its postulated role of connecting the two spatially separated photosystems (Jennings et al. 1979). His interest in the Mehler reaction, as a parallel electron transport and ATP generating process to NADP reduction, remained with him (e.g., Forti 1996) as well as the cyclic electron transport process and its regulation during state I/state II transitions (Finazzi et al. 1999).

Over the years, Giorgio taught the thoughts, skills, and the enthusiasm for photosynthetic research to his many students; a large number of them remained in the field, working both in Italy and overseas, and who in turn carried on, with success, the enthusiastic Forti tradition. In the '70s, he was an important mover in developing a biological biochemistry department at Milano. At that time biochemistry was almost exclusively associated with medical research in Italy. In 1970, he organized the second International Photosynthesis Congress at Stresa, on the Lago Maggiore in North Italy, in the era when specialist agencies dedicated to congress organization did not exist. All the organization was family and laboratory based. The congress, a great success, is remembered by its participants with pleasure.

This obituary would not be complete without mention of Giorgio Forti, the person. As a young adolescent he was engaged in the partisan conflict against the German forces, then occupying Italy. This had a profound effect on his world view, in a social and ethical sense. He was a fervid and active 'antifascist' and believed that social justice could only be achieved by the defeat of fascism in all its

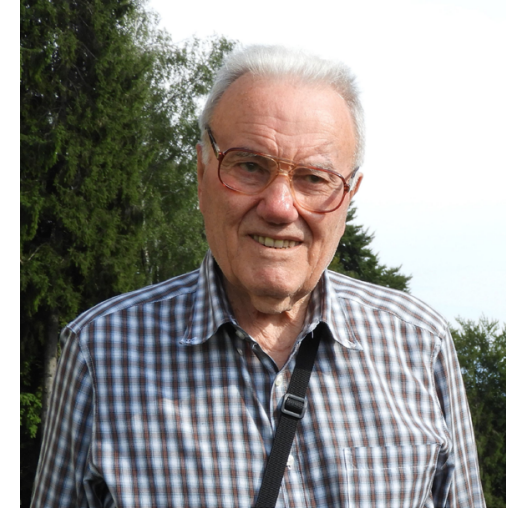

Prof. Giorgio Forti. Photo by Marina Forti.

varied forms. This conviction was not a matter limited to the ideological field. He was actively engaged, both in Italy and abroad, in movements aimed at improving the lot of the underprivileged and oppressed.

Giorgio, with his active enthusiasm for life and science, will be sadly missed.

\section{References}

Finazzi G., Furia A., Barbagallo R.P., Forti G.: State transitions, cyclic and linear electron transport and photophosphorylation in Chlamydomonas reinhardtii. - BBA-Bioenergetics 1413: 117-129, 1999.

Forti G.: Photosynthesis: an overview. - In: Jennings R.C., Zucchelli G., Ghetti F., Colombetti G. (ed.): Light as an Energy Source and Information Carrier in Plant Physiology. Pp. 1-16. Springer, Boston 1996.

Forti G., Jagendorf A.T.: Photosynthetic phosphorylation in the absence of redox dyes: Oxygen and ascorbate effects. Biochim. Biophys. Acta 54: 322-330, 1961.

Forti G., Parisi B.: Evidence for the occurrence of cyclic photophosphorylation in vivo. - Biochim. Biophys. Acta 71: 1-6, 1963.

Forti G., Sturani E.: On the structure and function of reduced nicotinamide adenine dinucleotide phosphate-cytochrome $f$ reductase of spinach chloroplasts. - Eur. J. Biochem. 3: 461-472, 1968.

Jennings R.C., Garlaschi F.M., Gerola P.D., Forti G.: Partition zone pentration by chymotrypsin and the localisation of the chloroplast flavoprotein and photosystem II. - BBABioenergetics 546: 207-219, 1979.

(C) The authors. This is an open access article distributed under the terms of the Creative Commons BY-NC-ND Licence. 